The projection of the head-clamp from the end of the table gives the surgeon and his assistant close access without obstruction.

\title{
A PLASTIC DISK FOR RETENTION OF A CORNEAL GRAFT*
}

B Y

\section{H. B. Stallard}

London

THE figure shows a transparent plastic disk shaped to the curvature of the cornea, $7 \mathrm{~mm}$. in diameter with four flanges notched on either side about $1.5 \mathrm{~mm}$. from their end, for the retention of sutures passed through the superficial half of the cornea. This disk affords reasonably secure fixation for a corneal graft and at the same time its transparency allows inspection of its edges at the operation and of its position afterwards.

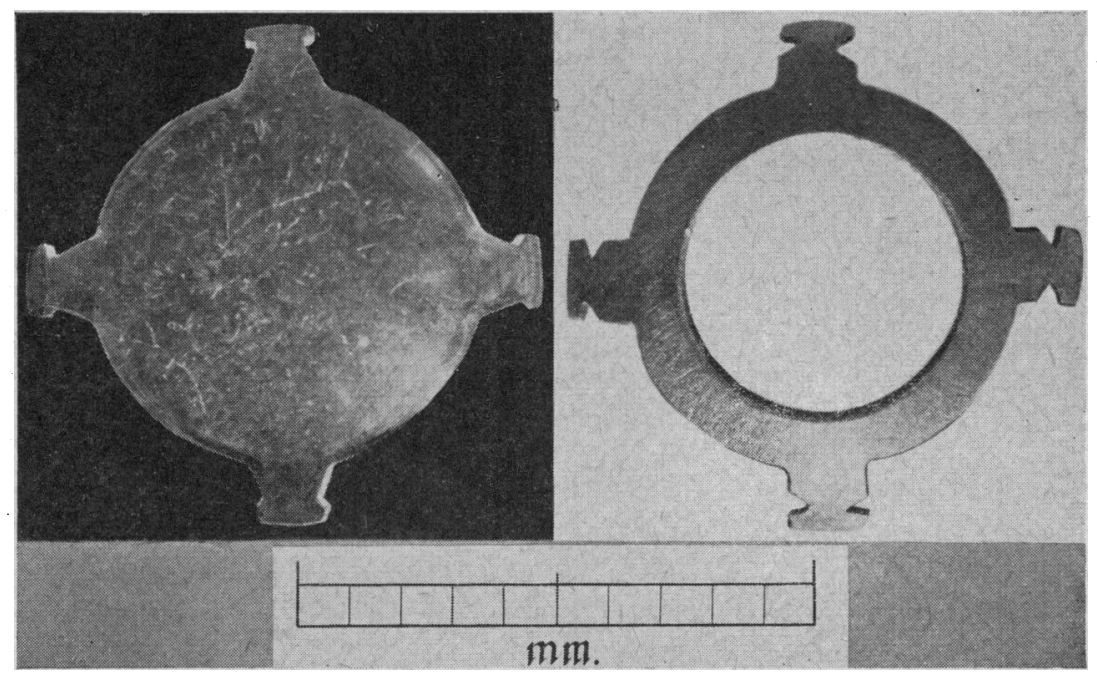

Figure.-On the left is a plastic disk. $7 \mathrm{~mm}$. diam., with four notched flanges. On the right is Pittar's tantalum ring for making the site of the graft. The trephine is placed inside the ring which it fits exactly.

The two disadvantages of Pittar's tantalum ring are that it prevents a view of the edge of the graft at the end of operation and afterwards, and that in this ring the centre of the graft is liable. to become oedematous and to be compressed forwards in the hole.

* Received for publication March 10, 1950. 